\title{
Coping Strategies and Trait Emotional Intelligence of Academic Staff
}

\author{
Marianna Marinaki, Alexander-Stamatios Antoniou, Nikos Drosos \\ National and Kapodistrian University of Athens, Athens, Greece \\ Email: marinaki16@hotmail.com
}

How to cite this paper: Marinaki, M., Antoniou, A. S., \& Drosos, N. (2017). Coping Strategies and Trait Emotional Intelligence of Academic Staff. Psychology, 8, 1455-1470.

https://doi.org/10.4236/psych.2017.810096

Received: June 26, 2017

Accepted: July 30, 2017

Published: August 2, 2017

Copyright $\odot 2017$ by authors and Scientific Research Publishing Inc. This work is licensed under the Creative Commons Attribution International License (CC BY 4.0).

http://creativecommons.org/licenses/by/4.0/

\begin{abstract}
This study examines the relationship between coping strategies and trait emotional intelligence of 548 academic staff employed in public universities in Greece Coping strategies were assessed by the Coping Scale of the Occupational Stress Indicator-OSI (Cooper, Sloan, \& Williams, 1988); and Trait Emotional Intelligence was measured by the Short form of the Trait Emotional Questionnaire/TEIQue-SF (Petrides, 2009a, 2009b). Academic staff reported high levels of trait emotional intelligence, and the results also indicated that there is a considerable diversity in the coping strategies that academics use. Most of the demographic variables were found not to differentiate academic staffs' trait emotional intelligence or coping styles. Trait emotional intelligence had medium to low positive correlations with all coping strategies. Results are discussed in terms of their practical implications.
\end{abstract}

\section{Keywords}

Trait Emotional Intelligence, Coping Strategies, Occupational Stress, Academic Staff, Greek Universities

\section{Introduction}

Academics generally work within a university, and their work combines research, teaching and administrative duties. Multiple duties and high competition make academia a rather stressful profession. Common sources of stress as identified by many studies (e.g. Abouserie, 1996; Blix, Cruise, Mitchell, \& Blix, 1994; Dua, 1994; Winefield et al., 2003) are: work overload, increased responsibilities and demands, unclear tenure and promotion criteria, increased competition and pressure for grants, publications and positions, peer assessments and public criticism, bureaucracy and poor administrative support, financial problems such as reduced funding, salary freezes and delayed retirement. Stress appears to have 
become a feature of academic staff's occupational life (Fisher, 1994). A series of studies in Australia and New Zealand found that academic staff experiences stress, psychological distress and negative health effects more often than the general population and non-academic staff (e.g. Boyd \& Wylie, 1994; Gillespie, Walsh, Winefield, Dua, \& Stough, 2001; Winefield, 2000; Winefield et al., 2003); whilst academics who were involved in only research or teaching reported reduced levels of stress compared to their colleagues who were engaged in both functions (Winefield \& Jarrett, 2001).

Studies in Britain presented similar findings confirming the high level of stress of academics in comparison to general population (Bradley \& Eachus, 1995; Kinman, 2001; Kinman \& Jones, 2003). In the United States, several studies highlighted the positive correlation between stress and behavioral, cognitive, emotional and physiological symptoms (Dua, 1994; Hogan, Carlson, \& Dua, 2002). Nevertheless, some studies (e.g. Doyle and Hind, 1998; Tytherleigh, 2003) found that although academics experience high level of stress and engage in long working hours, a large proportion of them still consider the job as essentially motivating, delightful and potentially beneficial. Academic staff is intrinsically motivated by the interest they have for their disciplines, and the related teaching and research tasks (Lacy \& Sheehan, 1997; McInnis, 1996, 1999).

Production of innovative research, publishing articles, and achieving citations are vital features of the academic profession and create additional stress to academics. Papers are evaluated by a system known as peer review, and subsequently academics are constantly under judgment. In order to become more recognizable and tenure positions with more prestige and job security, they attempt to author high-status publications. As a result, they need to write their papers in the English language, which in many cases is not their native language and therefore may represent a difficult task. Throughout the whole process networking is of major importance, as it can play a vital role in opening new opportunities (Lamont, 2009). External funding has become a very important factor (Geuna, 1999, 2001), due to years of cut in state funding for public universities. Professors who have achieved external financing tend to have more papers published compared to their colleagues who do not have external funding (Gulbrandsen \& Smeby, 2005). Previous studies have elicited contradictory results. Some studies showed that academics with external funding had more publications (e.g. Blumenthal et al., 1996; Godin, 1998), while others found very weak correlations (e.g. Kyvik, 1991). Nevertheless, the studies that identified weak connections were conducted in the early nineties, and the academic community has evolved since then. Thus, the importance of networking in order to find external funding has increased in recent years.

In Greece the current economic crisis has maximized the aforementioned stressors. In the last 7 years, academics have seen their salary being reduced by up to $31 \%$ (Feidas, 2016), while even before the crisis their salaries were was much below the EU average (Altbach et al., 2012; ACO, 2014; MORE, 2013). 
State funding for the Universities has also been reduced by more than $60 \%$ since 2009, while access to research grants has also been hardened (Feidas, 2016). Additionally, each year, Greek Universities tend to accept a greater number of new students than their infrastructure allows. The Greek Ministry of Education is responsible for running the country's education system including students' admission to the Universities, and although Universities suggest otherwise, it tends to ignore these suggestions. Currently the ratio is almost 30 students per professor while the EU average is $7-8$ students per professor as mentioned by the Dean of the University of Crete, Dr. Zoras, in an open letter to the Greek Minister of Education (10/04/2017). In 2013 there was a reduction of up to $45 \%$ of the administrative staff of the Universities (Official Government Gazette of Hellenic Republic, 2013a, 2013b, 2014), forcing the academic staff to undertake a much heavier administrative workload. Although the administrative difficulties were gradually reduced due to the return of the majority of the administrative staff, many malfunctions remained. Despite the aforementioned problems, academic staff in Greece has managed to achieve many distinctions and Greek Universities are among the 1000 top Universities worldwide (CWUR, 2016; Times Higher Education, 2016). It is clear that academics need appropriate coping mechanisms to address the high levels of stress that accompanies their profession.

\subsection{Coping Strategies}

Over the years, many studies have investigated the ways in which people manage stress in everyday life. Coping can be defined as the cognitive and behavioral efforts that people use in order to reduce the effects of stress (Lazarus \& Folkman, 1984). Attempting to categorize the various coping strategies, most authors recognize two broad types of coping: "approach" and "avoidant" strategies (e.g. Dempsey, Overstreet, \& Moley, 2000; Rosario, Salzinger, Feldman, \& Ng-Mak, 2003). While approach strategies try to address the problem by managing the stressor, avoidant strategies attempt to minimize the negative emotions by evading the stressor. In most cases approach coping strategies are considered functional (e.g. seeking information or advice, accepting social support, making efforts to solve the problem). On the other hand the avoidance coping strategies are considered dysfunctional (e.g. withdrawal, fatalistic attitudes, avoidance). Lazarus \& Folkman (1984) identify two other broad categories of coping strategies: problem-focused coping that aims at removing or circumventing the cause of the stress, and emotion-focused coping that aims at decreasing the negative emotions.

Although coping mechanisms have been extensively investigated, few studies have examined the coping strategies used by academic staff. Most studies among academic staff examine how professors can solve the problems that arise during teaching (Baiocco \& De Waters, 1998; De Waters, Baiocco, Ragonnet, 2005); rather than how they deal with various stressors. Abouserie (1996) investigated stress and coping strategies of academic staff and stressed that a wide variety of 
coping strategies were used, while Dunn (2006) and his colleagues examined how coping styles and social support are associated with the negative impact of perfectionism that affects considerably the daily routine of university professors. Nevertheless, these studies were conducted more than a decade ago, while no similar study has ever been conducted in Greece to the authors' knowledge.

\subsection{Trait Emotional Intelligence}

The construct of "emotional intelligence" (EI) gained much popularity in the mid-nineties with the publication of Daniel Goleman's book with this title (Goleman, 1995). The term "Emotional Intelligence" can be defined as a complex ability that includes monitoring one's own and other people's emotions, differentiating the various emotions and identifying them, and exhibiting the appropriate thinking and behavior. When facing a difficult situation, an emotionally intelligent person has self-awareness of his/her emotions and of other people's emotions. He/she will understand the dynamics of interpersonal relationships, by exhibiting the appropriate behavior (Mayer, 2008). Nevertheless, there is no general consensus for the operational definition of EI. Petrides \& Furnham $(2000,2001,2003)$ have proposed a distinction between: 1) trait EI (or "trait emotional self-efficacy") and 2) ability EI (or "cognitive-emotional stability"). The term "trait emotional intelligence" specifies a configuration of abilities and dispositions closely related to emotions that can be measured with self-report techniques, while ability emotional intelligence can be described as a constellation of cognitive abilities related to emotions that can be assessed with the use of maximum performance tests.

Emotional Intelligence is considered to be positively correlated to effective coping (Matthew \& Zeidner, 2001; Snyder \& Dinoff, 1999). A study of Furnham, Petrides \& Spencer-Bowdage (2002) has shown that EI is associated with healthy social coping styles. According to Gohm, Corse, \& Dalsky (2005), there is a negative correlation between EI and "avoidant" coping strategies, while there is a positive correlation between EI and "approach" coping strategies. Antoniou \& Drosos (2017) had similar findings in a recent study in Greece. Trait Emotional Intelligence was found to be positively correlated with positive coping, and negatively correlated with social withdrawal, blame and anger, and passive acceptance/ distraction. Nevertheless, there have been some recent studies that showed no correlation between ability EI and coping styles (Zeidner, Matthews, \& Olenick-Shemesh, 2016), and further research is needed.

Many studies recognize that it is very important for academics to deeply understand their students' mental and emotional state in order to be effective teachers. The necessity for professors to approach their students as individuals with different interests and abilities has been highlighted by various authors (e.g. Kugel, 1993). In a qualitative study that examined the reflection of six professors considered very skillful in their teaching, all participants held and used considerable knowledge about learners, as groups and as individuals. The aforemen- 
tioned knowledge was used to reflect the impact of their teaching (Mcalpine \& Weston, 2000). Despite the recognition of emotional intelligence's importance for academics (Mortiboys, 2002, 2012), there is a gap in the literature, and to the authors' knowledge emotional intelligence of academic staff has never been examined.

\subsection{The Present Study}

The present study examines coping strategies that Greek academic staff adopts in order to reduce stress. As stated above academics in Greek Universities face a lot of stressors due to the current harsh financial situation of Greece, and therefore they need to develop healthy coping mechanisms. Furthermore, the specific aim of the study is to investigate the level of academics' trait emotional intelligence and to explore the possible correlation between coping strategies and trait emotional intelligence. Identifying the relationship between these constructs may help Universities to provide suitable support to their academic staff in order to address their stress.

\section{Methodology}

\subsection{Participants}

The sample consisted of 548 academics (61.6\% males and 38.4\% females) working in Greek public Universities. Regarding their academic position, 56 of them (10.5\%) have the title of "Lecturer", 206 (38.7\%) have the title of "Assistant Professor", 138 (25.9\%) have the title of "Associate Professor", and 132 (24.8\%) have the title of "Full Professor". The average age of participants was 50.76 years, while the average years of teaching experience were 18.9 with a range from 1 to over 40 years. The vast majority of the participants is married (70.3\%), and has children (85.8\%).

\subsection{Measuring Instruments}

Coping Strategies were assessed by the "Stress Coping Strategies" of the Occupational Stress Indicator-OSI (Cooper, Sloan, \& Williams, 1988). The specific scale consists of 28 items designed to assess the positive and negative aspects of coping strategies. Individuals are asked to evaluate various stressful situations on a six-point Likert type scale ranging from 1 ("I do not use this option/way") to 6 ("I always use this option/way"). The Scale provides scores for the following six subscales: 1) "Social Support": the assistance which an individual may have from the development of a social network (Cronbach's $\alpha=.47) ; 2$ ) "Task Strategies": the individual's efforts to cope with occupational stress by rearranging his/her current and future tasks (Cronbach's $\alpha=.61$ ); 3) "Logic": the individual's unemotional and rational approach to stressful situations in order to solve the problem (Cronbach's $\alpha=.64) ; 4$ ) "Home/Work Relationships": the individual's efforts to reduce stress by deriving support from the home environment and from other pleasant activities (Cronbach's $\alpha=.57)$; 5) "Time": the individual 
uses effective time management as a way to reduce stress (Cronbach's $\alpha=.69$ ); and 6) "Involvement": the individual's ways of approaching the tasks that create stress (Cronbach's $\alpha=.54$ ). Items 6, 10, 11, 20, 24 and 25 were excluded due to poor psychometric properties.

Trait Emotional Intelligence was measured with the short form of the Trait Emotional Intelligence Questionnaire (TEIQue-SF) (Petrides, 2009a, 2009b). TEIQue-SF is a 30-item questionnaire designed to measure global trait emotional intelligence, and it is based on the full form of the TEIQue, which covers 15 distinct facets. Two items from each of the 15 subscales (facets) of the TEIQue are included in the short form of the instrument. Individuals are asked to rate the statements on a seven-point Likert-type scale ranging from 1 ("strongly disagree") to 7 ("strongly agree"). A global trait EI score is calculated by summing up the item scores and dividing by the total number of items (Cronbach's a $=.86)$. The TEIQue-SF does not yield scores on the 15 trait EI facets. Although the TEIQue-SF measures global trait EI, four subscales can be derived. The four subscales are: well-being (Cronbach's $\alpha=.74$ ), self-control (Cronbach's $\alpha=.58$ ), emotionality (Cronbach's $\alpha=.62$ ), and sociability (Cronbach's $\alpha=.69$ ). Items 3, 18,14 , and 29 contribute only to the global trait EI score without belonging to a specific subscale (Petrides, 2009a).

The last section of the questionnaire administered to academics refers to general questions including their gender, age, marital status, academic position, years of practicing their profession, etc.

\subsection{Procedure}

After gaining permission from the General Assemblies of the various Departments of each University, the questionnaires were sent to academic staff by email. Written instructions were given describing the procedure and the aim of the research. Participants were kindly requested to answer all questions as honestly and as spontaneously as possible. They were given reassurance that all answers would be confidential and all data would be used solely for research purposes. Furthermore, preservation of anonymity was ensured.

\section{Results}

Descriptive statistics were used for all variables of our study. Table 1 shows the means of the scores of academics for the six coping strategies. All scores were somewhat high ranging between $\mathrm{M}=4.34$ ("Social Support", S.D. = .90) and $\mathrm{M}$ $=4.59$ ("Task Strategies", S.D. = .70 and "Logic", S.D. = .97). The only exception was "Home and Work Relationships" that had the lowest score (M = 3.80, S.D. = 1.16). These findings suggest that academics use a wide variety of coping mechanisms in order to reduce stress.

Table 1 also shows the means of the scores of academics in the TEIQue-SF. As indicated, the mean score is rather high in all trait EI factors. "Emotionality" had the highest score, while "Well-being" was very close. "Self-control" and 
Table 1. Means of coping strategies as a function of academic position and gender.

\begin{tabular}{|c|c|c|c|c|c|c|c|c|c|c|}
\hline & & $T$ & & & demic Positi & & & & Gender & \\
\hline & ables & & Lecturer & Assist. Prof. & Assoc. Prof. & Full Prof. & & Male & Female & \\
\hline & & $M$ & $M$ & $M$ & $M$ & $M$ & $F$ & $M$ & $M$ & $F$ \\
\hline & Well-being & 5.15 & 5.12 & 5.22 & 5.21 & 5.02 & 1.04 & 5.17 & 5.12 & .21 \\
\hline & Self-control & 4.86 & 4.78 & 4.84 & 4.96 & 4.88 & .70 & 4.85 & 4.87 & .05 \\
\hline TEIQue-SF & Emotionality & 5.21 & 5.23 & 5.26 & 5.26 & 5.14 & .60 & 5.09 & 5.35 & $10.43^{\star *}$ \\
\hline & Sociability & 4.44 & 4.31 & 4.44 & 4.44 & 4.46 & .36 & 4.47 & 4.35 & 1.65 \\
\hline & Global Trait EI & 5.04 & 4.98 & 5.07 & 5.10 & 5.01 & .58 & 5.01 & 5.07 & .94 \\
\hline & Social Support & 4.34 & 4.36 & 4.41 & 4.35 & 4.31 & .31 & 4.20 & 4.52 & $12.70^{\star *}$ \\
\hline & Task Strategies & 4.59 & 4.53 & 4.56 & 4.60 & 4.70 & .55 & 4.57 & 4.63 & 1.00 \\
\hline Coning & Logic & 4.59 & 4.41 & 4.52 & 4.62 & 4.68 & 1.23 & 4.64 & 4.46 & 3.31 \\
\hline Strategies & $\begin{array}{l}\text { Home \& Work } \\
\text { Relationships }\end{array}$ & 3.80 & 3.96 & 3.73 & 3.90 & 3.72 & 1.04 & 3.85 & 3.80 & .23 \\
\hline & Time & 4.37 & 4.26 & 4.36 & 4.40 & 4.51 & .91 & 4.37 & 4.40 & .07 \\
\hline & Involvement & 4.36 & 4.31 & 4.36 & 4.35 & 4.45 & .59 & 4.31 & 4.43 & 2.94 \\
\hline
\end{tabular}

Note $1:{ }^{*}=p<.001$; Note 2 : TEIQue minimum possible score $=1$; TEIQue maximum possible score $=7$; Coping minimum possible score $=1$; Coping maximum possible score $=6$.

"Sociability" followed with small differences in their scores. The findings suggest that academics have a rather high level of trait emotional intelligence.

Two-way analyses of variance were conducted to examine the effect of gender and academic position (lecturer, assistant professor, associate professor, and full professor) on both coping strategies and the various factors of trait emotional intelligence. There was no statistically significant interaction between the effects of gender and academic position on neither coping strategies nor trait emotional intelligence. Main effects analysis showed that females had significantly higher scores than males for "Emotionality" $(p<.001)$. Additionally, females had significantly higher score than males for "Social Support" $(p<.001)$. No other significant difference as a function of gender or academic position was identified.

T-Tests were performed to examine whether academics' marital status differentiates the scores for trait EI or coping strategies. Academics' marital status differentiated the scores in only one trait EI factor $(\mathrm{t}=2.54 \mathrm{df}=538, p<.05)$. Unmarried academics had a lower score $(\mathrm{M}=4.99$, S.D. $=1.08)$ than their married colleagues $(\mathrm{M}=5.23$, S.D. $=.97)$ in "Well-being"). Regarding the coping strategies, marital status was found to differentiate the scores in "Task Strategies" $(\mathrm{t}=2.24, \mathrm{df}=505, p<.05)$ and in "Logic" $(\mathrm{t}=2.12, \mathrm{df}=524, p<.05)$. In "Task Strategies" unmarried academics had a lower score $(\mathrm{M}=4.49$, S.D. $=.77)$ than their married colleagues $(M=4.64$, S.D. $=.66)$. Finally, for "Logic" unmarried academics also presented lower score $(M=4.45$, S.D. $=.77)$ than their married colleagues $(M=4.65$, S.D. $=.66)$.

One-way ANOVAs were performed in order to examine whether age differen- 
tiates the scores of trait EI or coping strategies. No significant age effect was found. One-way ANOVAs were also performed to investigate whether experience (years of working in the University) was associated with trait EI or coping strategies. No significant effect of experience was found.

To examine the relationship between coping strategies and trait emotional intelligence, correlation coefficients were calculated. As shown in Table 2, all coping strategies have low to medium significant positive correlations (ranging from $\mathrm{r}=.09, p<.05$ to $\mathrm{r}=.46, p<.001)$ with all trait EI factors:

- "Social Support" has a low positive correlation with "Emotionality" ( $\mathrm{r}=.19$, $p<.01)$, "Self-control" ( $\mathrm{r}=.09, p<.05)$, "Well-being" $(\mathrm{r}=.23, p<.01)$, "Sociability" ( $\mathrm{r}=.11, p<.05)$, and global trait EI $(\mathrm{r}=.22, p<.01)$.

- "Task Strategies" have a low positive correlation with "Emotionality" $(\mathrm{r}=.21$, $p<.01)$, and medium positive correlations with "Self-control" $(\mathrm{r}=.33, p$ $<.01)$, "Well-being" $(\mathrm{r}=.35, p<.01)$, "Sociability" ( $\mathrm{r}=.36, p<.01)$, and global trait EI $(\mathrm{r}=.45, p<.01)$.

- "Logic" has a low positive correlation with "Emotionality" $(\mathrm{r}=.25, p<.01)$, and medium positive correlations with "Self-control" $(\mathrm{r}=.42, p<.01)$, "Well-being" ( $\mathrm{r}=.35, p<.01)$, "Sociability" $(\mathrm{r}=.32, p<.01)$, and global trait EI $(\mathrm{r}=.46, p<.01)$.

- "Home and Work Relationships" have a low positive correlation with "Emotionality" $(\mathrm{r}=.25, p<.01)$, "Well-being" $(\mathrm{r}=.29, p<.01)$, and "Sociability" $(\mathrm{r}=.23, p<.01)$, and medium positive correlations with "Self-control" $(\mathrm{r}$ $=.30, p<.01)$, and global trait $\mathrm{EI}(\mathrm{r}=.37, p<.01)$.

- "Time" has a low positive correlation with "Emotionality" $(\mathrm{r}=.28, p<.01)$, and "Well-being" ( $\mathrm{r}=.27, p<.01)$, and medium positive correlations with and "Sociability" ( $\mathrm{r}=.36, p<.01)$, "Self-control" $(\mathrm{r}=.40, p<.01)$, and global trait $\mathrm{EI}(\mathrm{r}=.45, p<.01)$.

- "Involvement" has a low positive correlation with "Emotionality" $(\mathrm{r}=.24, p$ $<.01)$, "Self-control" $(\mathrm{r}=.26, p<.01)$, and "Sociability" $(\mathrm{r}=.22, p<.01)$, and medium positive correlations with "Well-being" ( $\mathrm{r}=.33, p<.01)$, and global trait $\mathrm{EI}(\mathrm{r}=.38, p<.01)$.

\section{Discussion}

The present study explored coping strategies used by academic staff in Greece when facing stressful situations. In addition, the study examined the relationship between coping strategies and trait emotional intelligence. As extensively discussed in the introduction section of this paper, academic staff in Greece face many difficulties associated with their multitasking duties, and the lack of infrastructure and support due to Greece's current economic crisis, which could function as major stressors. Therefore the importance of investigating the mechanisms that they use to reduce stress is evident.

Results suggest that academics in Greece use a wide variety of coping mechanisms. This finding is in accordance to Abouserie's study on academic staff 
Table 2. Correlation coefficients (Pearson $r$ ) between TEIQue-SF factors and the coping mechanisms.

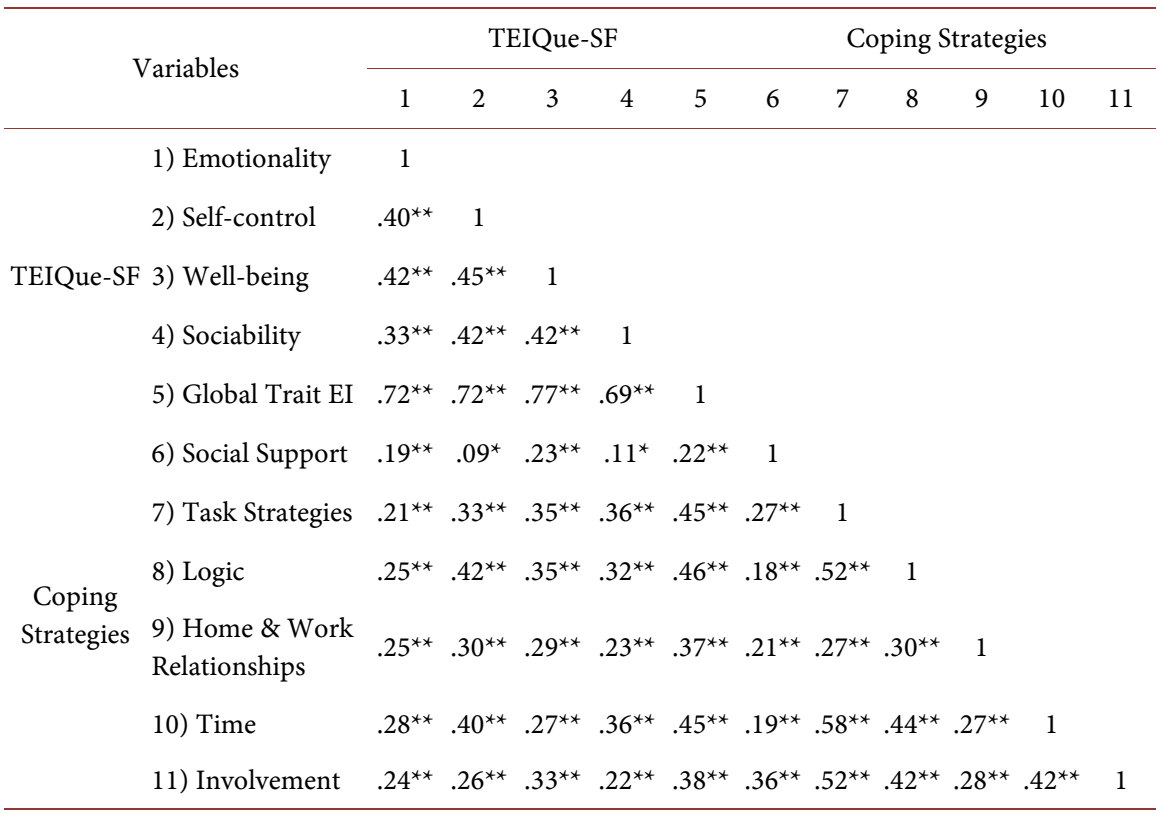

Note $1:^{*}=p<.05 ;{ }^{*}=p<.01$.

in Britain (1996). The most predominant coping strategies suggested active efforts to reduce stress by organizing job tasks and setting priorities and by following a rational approach to solve the potential problems ("Task strategies" and "Logic"). Additionally, academics frequently utilize the following as coping mechanisms: effective time management, active involvement to solve the problem, and assistance from their social support system. Other studies in Greek Primary and Secondary Education teachers (Antoniou, Ploumpi, \& Ntalla, 2013) and Special Education teachers (Antoniou, Polychroni, \& Kotroni, 2009) have also identified the use of positive and active approaches that aim to solve the problem. This could explain that, despite the increased difficulties that Greek academics face, the quality of their job has not been correspondingly affected. A recent analysis (Sachini et al., 2015) of Greek publications' citation impact indicator showed that Greece has surpassed the OECD countries' citation impact and is just below reaching the EU average.

The less frequently used coping strategy was found to be the individual's efforts to reduce stress by deliberately separating "home" and "work" and expanding interests and developing hobbies. This avoidant strategy may briefly reduce stress, but in the long-term is not very helpful because the stressors remain and if not addressed the problems may be likely to increase even more. As one of the main stressors of academic staff is work overload and the necessity of publishing articles, it is possible that they lack the opportunity to expand their interests in other areas or to be engaged in hobbies. Nevertheless, we should note that although this strategy is used less than others, the score was not particularly low, suggesting that academics do have some activities and hobbies other than their work. 
Regarding individual differences, our study suggests that female academics seek support from their social support environment more often than their male colleagues. The literature further demonstrates that women tend to be more engaged in their social networks and gain more benefit by seeking out and using social support than men (Antoniou et al., 2009; Glynn, Christenfeld, \& Gerin, 1999; Taylor et al., 2000). No other significant gender differences were identified in the present study with regards to the usage of specific coping strategies. Additionally, no other variable (e.g. participants' age, work experience, academic position) was found to differentiate the use of coping strategies among academics. However, other studies (Abouserie, 1996; Dua, 1994) have suggested that younger or lower level academics (e.g. lecturers) experience higher level of stress but they had either not investigated coping mechanisms or not found differences. In future research, it would be interesting to investigate the relationship of stress levels of academics with the various coping strategies.

Academics reported medium to high levels of trait emotional intelligence. As the academic profession includes teaching and supervising students, the ability of academics to understand themselves and others; and to approach relationships effectively is of great importance. Therefore this high score was to be expected, as other studies among teachers have also shown (e.g. Platsidou, 2010). Nevertheless, our study found that the lower score of trait EI was on the Sociability factor. Sociability describes how comfortable an individual is when interacting with others in different social contexts, from casual social gatherings to formal business meetings; and his/ her confidence for dealing with diverse sorts of people, influencing others, and subsequently motivating them. It is possible that this finding reflects the stress associated with the increasing need for networking and obtaining funds for research.

Almost no demographic variables (academic position, age, and years of experience) were found to have effects on scores of trait EQ. These findings are consistent with relevant literature. Females achieved higher score than males for "emotionality" only, which includes empathy, emotion perception and expression as well as a compassionate response to others' feelings. According to Goleman (1998), men and women do not differ in emotional intelligence as a whole. Nevertheless he acknowledged that there are gender differences in some aspects of emotional intelligence. Other research findings suggest that women tend to score higher than men on some aspects of emotional intelligence, while on other aspects men tend to score higher than women (Bar-On, 1997; Bar-On et al., 2000; Dawda \& Hart, 2000; Petrides \& Furnham, 2000). It should be noted that in some cases women were found to report higher scores in general (Mandell \& Pherwani, 2003; Mayer \& Geher, 1996; Mayer et al., 1999), but in these cases higher scores were measured with an ability-based assessment instrument (Mayer-Salovey-Caruso Emotional Intelligence Test), instead of a self-report questionnaire.

Trait emotional intelligence had medium positive correlations with all coping 
strategies, except for seeking social support where the positive correlation was significant but low. The association between trait EI with the various active strategies, such as rearrangement of the current and future tasks, rational approach of the problems, effective time management, and active involvement, comes as no surprise. These findings are similar to previous studies (e.g. Antoniou \& Drosos, 2017; Matthew \& Zeidner, 2001; Snyder \& Dinoff, 1999; Furnham, Petrides, \& Spencer-Bowdage, 2002; Gohm, Corse, \& Dalsky, 2005; Petrides et al., 2007) that have suggested a positive relationship with "healthy" coping styles. Nevertheless, it should be noted that some of the subscales of the scale that we used for the measurement of coping strategies do not allow for a clear distinction between strategies that aim to solve the problems and strategies aimed at emotion. For example, the use of social support as a means of reducing stress can be regarded both as seeking sympathy, and understanding (emotion focused), and as seeking advice, assistance or information (problem focused).

\section{Conclusion}

It seems that academics in Greece use a wide variety of coping strategies in order to deal with the important stressors that they face. It is worth mentioning that the most often reported strategies are aiming at solving the problems. Therefore this finding can explain the "how", regardless the major difficulties that Greek Universities face, the quality of academics' work has remained high. Nevertheless, their personal life seems to be affected as the least coping strategy used by academics was the "separation" of home and work life, e.g. by having hobbies. So, academics in Greece have the work overload that we presented in the first section of the present study, and in the same time they continue to work or thinking about the work even after they have returned home. Although this finding needs to be further investigated by future studies, it suggests the need to facilitate the work-life balance for academic staff.

Academics appear to have quite high trait emotional intelligence, which can be regarded as a positive result. Academics have also teaching and supervising duties, and EI is of major importance. Our study found a positive correlation between healthy coping strategies and trait EI, and it helps gaining a better understanding of the relationship between these constructs. The results of this study may help Greek academics to gain insights about their own feelings and the coping procedures which they follow. Moreover, these identifications could help to formulate suggestions and propositions in order to develop effective intervention programs suitable for the specific needs of academic staff. Furthermore, teaching programs should be based on the knowledge and skills which are considered essential taking into consideration academics' multiple duties and increased workload. The findings of the current study provide an insightful contribution regarding the adjustments that should be made by the government in order to ameliorate the educational structure in Greece and thus reduce the relevant source of stress. 


\section{Limitations and Future Research}

The measuring instruments used in our study were all self-report assessment tools, and thus we cannot exclude positive or negative bias in participants' responses. Nevertheless, our study highlights the necessity for further research in order to better understand the coping mechanisms of academic staff. Further investigation is needed to examine whether they exhibit the same mechanisms in different environments and stressors (e.g. work, family etc.). Future research should also aim at examining academics levels of stress in various environments.

\section{References}

AAbouserie, R. (1996). Stress, Coping Strategies and Job Satisfaction in University Academic Staff. Educational Psychology, 16, 49-56.

https://doi.org/10.1080/0144341960160104

ACO (Academic Careers Observatory) (2014). Academic Careers Observatory of the European University Institute.

http://www.eui.eu/ProgrammesAndFellowships/AcademicCareersObservatory/Acade micCareersbyCountry/Index.aspx

Altbach, P. G., Reisberg, L., Yudkevich, M., Androushchak, G., \& Pacheco, I. F. (2012). Paying the Professoriate: A Global Comparison of Compensation and Contracts. New York: Routlege.

Antoniou, A. S., \& Drosos, N. (2017). Coping Strategies of Greek 6th Grade Students: Their Relationship with Anxiety and Trait Emotional Intelligence. International Journal of Learning, Teaching and Educational Research, 16, 57-71.

Antoniou, A. S., Ploumpi, A., \& Ntalla, M. (2013). Occupational Stress and Professional Burnout in Teachers of Primary and Secondary Education: The Role of Coping Strategies. Psychology, 4, 349-355. https://doi.org/10.4236/psych.2013.43A051

Antoniou, A. S., Polychroni, F., \& Kotroni, C. (2009). Working with Students with Special Educational Needs in Greece: Teachers' Stressors and Coping Strategies. International Journal of Special Education, 24, 100-111.

Baiocco, S. A., \& De Waters, J. N. (1998). Successful College Teaching: Problem-Solving Strategies of Distinguished Professors. Needham Heights, MA: Allyn \& Bacon.

Bar-On, R. (1997). Bar-On Emotional Quotient Inventory (EQ-I): Technical Manual. Toronto: Multi-Health Systems.

Bar-On, R., Brown, J., Kirkcaldy, B., \& Thome, E. (2000). Emotional Expression and Implications for Occupational Stress: An application of the Emotional Quotient Inventory (EQ-I). Personality and Individual Differences, 28, 1107-1118. https://doi.org/10.1016/S0191-8869(99)00160-9

Blix, A. G., Cruise, R. J., Mitchell, B. M., \& Blix, G. G. (1994). Occupational Stress among University Teachers. Educational Research, 36, 157-169. https://doi.org/10.1080/0013188940360205

Blumenthal, D., Campbell, E. G., Causino, N., \& Louis, K. S. (1996). Participation of LifeScience Faculty in Research Relationships with Industry. New England Journal of Medicine, 335, 1734-1739. https://doi.org/10.1056/NEJM199612053352305

Boyd, S., \& Wylie, C. (1994). Workload and Stress in New Zealand Universities. Wellington: New Zealand Council for Educational Research and the Association of University Staff of New Zealand. 
Bradley, J., \& Eachus, P. (1995). Occupational Stress within a UK Higher Education Institution. International Journal of Stress Management, 2, 145-158. https://doi.org/10.1007/BF01740300

Cooper, C. L., Sloan, S. L., \& Williams, S. L. (1988). Occupational Stress Indicator Management Guide. Windsor: Nfer-Nelson.

CWUR (Center for World University Rankings) (2016). CWUR 2016-World University Rankings. http://cwur.org/2016.php

Dawda, D., \& Hart, S. D. (2000). Assessing Emotional Intelligence: Reliability and Validity of the Bar-On Emotional Quotient Inventory (1997a; 2000) in University Students. Personality and Individual Differences, 28, 797-812. https://doi.org/10.1016/S0191-8869(99)00139-7

Dempsey, M., Overstreet, S., \& Mley, B. (2000). “Approach” and “Avoidance” Coping and PTSD Symptoms in Inner-City Youth. Current Psychology, 19, 28-45. https://doi.org/10.1007/s12144-000-1002-Z

De Waters, J. N., Baiocco, S. A., \& Ragonnet, J. L. (2005). Successful College Teaching: Problem-Solving Strategies of Distinguished Professors (2nd ed.). Charlottesville, VA: Cllegiate Development Network.

Doyle, C., \& Hind, P. (1998). Occupational Stress, Burnout and Job Status in Female Academics. Gender, Work and Organisation, 5, 67-82.

https://doi.org/10.1111/1468-0432.00047

Dua, J. K. (1994). Job Stressors and Their Effects on Physical Health, Emotional Health, and Job Satisfaction in a University. Journal of Educational Administration, 32, 59-78. https://doi.org/10.1108/09578239410051853

Dunn, J. C., Whelton, W. J., \& Sharpe, D. (2006). Maladaptive Perfectionism, Hassles, Coping, and Psychological Distress in University Professors. Journal of Counseling Psychology, 53, 511-523. https://doi.org/10.1037/0022-0167.53.4.511

Feidas, C. (2016). The Salaries State of University Academic Staff in Greece. Thessaloniki: Aristotle University of Thessaloniki.

Fisher, S. (1994). Stress in Academic Life: The Mental Assembly Line. Buckingham: SHRE and Open University Press.

Furnham, A., Petrides, K., \& Spencer-Bowdage, S. (2002). The Effects of Different Types of Social Desirability on the Identification of Repressors. Personality and Individual Differences, 33, 119-130. https://doi.org/10.1016/S0191-8869(01)00139-8

Geuna, A. (1999). The Economics of Knowledge Production. Funding and the Structure of University Research. Cheltenham: Edward Elgar.

Geuna, A. (2001). The Changing Rationale for European University Research Funding: Are There Negative Unintended Consequences? Journal of Economic Issues, 35, 607632. https://doi.org/10.1080/00213624.2001.11506393

Gillespie, N. A., Walsh, M., Winefield, A. H., Dua, J., \& Stough, C. (2001). Occupational Stress in Universities: Staff Perceptions of the Causes, Consequences and Moderators of Stress. Work and Stress, 15, 53-72. https://doi.org/10.1080/02678370117944

Glynn, L. M., Christenfeld, N., \& Gerin, W. (1999). Gender, Social Support, and Cardiovascular Responses to Stress. Psychosomatic Medicine, 61, 234-242. https://doi.org/10.1097/00006842-199903000-00016

Godin, B. (1998). Writing Performative History: The New Atlantis? Social Studies of Science, 28, 465-483. https://doi.org/10.1177/030631298028003004

Gohm, C. L., Corse, G. C., \& Dalsky, D. J. (2005). Emotional Intelligence under Stress: Useful, Unnecessary, or Irrelevant? Personality and Individual Differences, 39, 1017- 
1028. https://doi.org/10.1016/j.paid.2005.03.018

Goleman, D. (1995). Emotional Intelligence. New York: Bantam Books.

Goleman, D. (1998). Working with Emotional Intelligence. New York: Bantam.

Gulbrandsen, M., \& Smeby, J. C. (2005). Industry Funding and University Professors' Research Performance. Research Policy, 34, 932-950. https://doi.org/10.1016/j.respol.2005.05.004

Hogan, J. M., Carlson, J. G., \& Dua, J. (2002). Stressors and Stress Reactions among University Personnel. International Journal of Stress Management, 9, 289-310. https://doi.org/10.1023/A:1019982316327

Kinman, G. (2001). Pressure Points: A Review of Stressors and Strains in UK Academics. Educational Psychology, 21, 474-492. https://doi.org/10.1080/01443410120090849

Kinman, G., \& Jones, F. (2003). 'Running up the Down Escalator': Stressors and Strains in UK Academics. Quality in Higher Education, 9, 22-38. https://doi.org/10.1080/13538320308162

Kugel, P. (1993). How Professors Develop as Teachers. Studies in Higher Education, 18, 315-328. https://doi.org/10.1080/03075079312331382241

Kyvik, S. (1991). Productivity in Academia. Scientific Publishing at Norwegian Universities. Oslo: Scandinavian University Press.

Lacy, F. J., \& Sheehan, B. A. (1997). Job Satisfaction among Academic Staff: An International Perspective. Higher Education, 34, 305-322. https://doi.org/10.1023/A:1003019822147

Lamont, M. (2009). How Professors Think: Inside the Curious World of Academic Judgment. Cambridge, MA: Harvard University Press. https://doi.org/10.4159/9780674054158

Lazarus, R. S., \& Folkman, S. (1984). Stress Appraisal and Coping. New York: Springer.

Mandell, B., \& Pherwani, S. (2003). Relationship between Emotional Intelligence and Transformational Leadership Style: A Gender Comparison. Journal of Business and Psychology, 17, 387-404. https://doi.org/10.1023/A:1022816409059

Matthew, G., \& Zeidner, M. (2001). Emotional Intelligence, Adaptation to Stressful Encounters \& Health Outcomes. In R. Bar-On, \& J. D. A. Parker (Eds.), The Handbook of Emotional Intelligence. San Francisco, CA: Jossey-Bass/Pfeiffer.

Mayer, J. D. (2008). Emotional Intelligence: New Ability or Eclectic Traits? American Psychologist, 63, 503-517. https://doi.org/10.1037/0003-066X.63.6.503

Mayer, J. D., \& Geher, G. (1996). Emotional Intelligence and the Identification of Emotion. Intelligence, 22, 89-113. https://doi.org/10.1016/S0160-2896(96)90011-2

Mayer, J. D., Caruso, D., \& Salovey, P. (1999). Emotional Intelligence Meets Traditional Standards for Intelligence. Intelligence, 27, 267-298. https://doi.org/10.1016/S0160-2896(99)00016-1

Mcalpine, L., \& Weston, C. (2000). Reflection: Issues Related to Improving Professors' Teaching and Students' Learning. Instructional Science, 28, 363-385. https://doi.org/10.1023/A:1026583208230

McInnis, C. (1996). Change and Diversity in the Work Patterns of Australian Academics. Higher Education Management, 8, 105-117.

McInnis, C. (1999). The Work Roles of Academics in Australian Universities. Melbourne: Department of Education, Training and Youth Affairs.

MORE (2013). Support for Continued Data Collection and Analysis Concerning Mobility Patterns and Career Paths of Researchers. 
https://cdn2.euraxess.org/sites/default/files/policy_library/report_on_survey_of_resear chers_in_eu_hei.pdf

Mortiboys, A. (2002). The Emotionally Intelligent Lecturer: SEDA Special 12. Birmingham: SEDA Publications.

Mortiboys, A. (2012). Teaching with Emotional Intelligence (2nd ed.). London \& New York: Routledge.

Official Government Gazette of Hellenic Republic (2013a). No 135211/B2/23.9.2013 (B'2384) Joint Decision of the Minister of Education and Religious Affairs and of the Minister of Administrative Reform and E-Government. Athens: Benakeios Library.

Official Government Gazette of Hellenic Republic (2013b). No 150539/B2/15.10.2013 (B'2601) Joint Decision of the Minister of Education and Religious Affairs and of the Minister of Administrative Reform and E-Government. Athens: Benakeios Library.

Official Government Gazette of Hellenic Republic (2014). No 57519/B2/11.04.2014 (B'910) Joint Decision of the Minister of Education and Religious Affairs and of the Minister of Administrative Reform and E-Government. Athens: Benakeios Library.

Petrides, K. V. (2009a). Technical Manual for the Trait Emotional Intelligence Questionnaires (TEIQue). London: London Psychometric Laboratory.

Petrides, K. V. (2009b). Psychometric Properties of the Trait Emotional Intelligence Questionnaire. In C. Stough, D. H. Saklofske, \& J. D. Parker (Eds.), Advances in the Assessment of Emotional Intelligence (pp. 21-33). New York: Springer.

https://doi.org/10.1007/978-0-387-88370-0_5

Petrides, K. V., \& Furnham, A. (2000). On the Dimensional Structure of Emotional Intelligence. Personality and Individual Differences, 29, 313-320.

https://doi.org/10.1016/S0191-8869(99)00195-6

Petrides, K. V., \& Furnham, A. (2001). Trait Emotional Intelligence: Psychometric Investigation with Reference to Established Trait Taxonomies. European Journal of Personality, 15, 425-448. https://doi.org/10.1002/per.416

Petrides, K. V., Pérez-González, J. C., \& Furnham, A. (2007). On the Criterion and Incremental Validity of Trait Emotional Intelligence. Cognition and Emotion, 21, 26-55. https://doi.org/10.1080/02699930601038912

Petrides, K., \& Furnham, A. (2003). Trait Emotional Intelligence: Behavioural Validation in Two Studies of Emotion Recognition and Reactivity to Mood Induction. European Journal of Personality, 17, 39-57. https://doi.org/10.1002/per.466

Platsidou, M. (2010). Trait Emotional Intelligence of Greek Special Education Teachers in Relation to Burnout and Job Satisfaction. School Psychology International, 31, 60-76. https://doi.org/10.1177/0143034309360436

Rosario, M., Salzinger, S., Feldman, R. S., \& Ng-Mak, D. S. (2003). Community Violence Exposure and Delinquent Behaviors among Youth: The Moderating Role of Coping. Journal of Community Psychology, 31, 489-512. https://doi.org/10.1002/jcop.10066

Sachini, E., Malliou, N., Karampekios, N., \& Karaiskos, D. (2015). Greek Scientific Publications 1998-2012: A Bibliometric Analysis of Greek Publications in International Scientific Journals - Scopus. Athens: National Documentation Center.

Snyder, C. R., \& Dinoff, B. L. (1999). Coping: Where Have You Been? In C. R. Snyder (Ed.), Coping: The Psychology of What Works (pp. 3-19). New York: Oxford University Press. https://doi.org/10.1093/med:psych/9780195119343.001.0001

Taylor, S. E., Klein, L. C., Lewis, B. P., Gruenewald, T. L., Gurung, R. A. R., \& Updegraff, J. A. (2000). Biobehavioral Responses to Stress in Females: Tend-and-Befriend, Not Fight-or-Flight. Psychological Review, 107, 441-429. 
https://doi.org/10.1037/0033-295X.107.3.411

Times Higher Education (2016). World University Rankings 2015-2016. https://www.timeshighereducation.com/world-university-rankings/2016/world-rankin g

Tytherleigh, M. Y. (2003). What Employers May Learn from English Higher Education Institutions: A Fortigenic Approach to Occupational Stress. SA Journal of Industrial Psychology, 29, 101-106. https://doi.org/10.4102/sajip.v29i4.130

Winefield, A. H. (2000). Stress in Academe: Some Recent Research Findings. In D. T. Kenny, J. G. Carlson, F. J. McGuigan, \& J. L. Sheppard (Eds.), Stress and Health (pp. 437-446). Amsterdam: Harwood Academic Publishers.

Winefield, A. H., \& Jarrett, R. (2001). Occupational Stress in University Staff. International Journal of Stress Management, 8, 285-298. https://doi.org/10.1023/A:1017513615819

Winefield, A., Gillespie, N., Stough, C., Dua, J., Hapuararchchi, J., \& Boyd, C. (2003). Occupational Stress in Australian University Staff: Results from a National Survey. International Journal of Stress Management, 10, 51-63. https://doi.org/10.1037/1072-5245.10.1.51

Zeidner, M., Matthews, G., \& Olenick-Shemesh, D. (2016). Cognitive-Social Sources of Wellbeing: Differentiating the Roles of Coping Style, Social Support, and Emotional Intelligence. Journal of Happiness Studies, 17, 2481-2501.

https://doi.org/10.1007/s10902-015-9703-z

\section{Submit or recommend next manuscript to SCIRP and we will provide best} service for you:

Accepting pre-submission inquiries through Email, Facebook, LinkedIn, Twitter, etc. A wide selection of journals (inclusive of 9 subjects, more than 200 journals)

Providing 24-hour high-quality service

User-friendly online submission system

Fair and swift peer-review system

Efficient typesetting and proofreading procedure

Display of the result of downloads and visits, as well as the number of cited articles Maximum dissemination of your research work

Submit your manuscript at: http://papersubmission.scirp.org/

Or contact psych@scirp.org 